\title{
Pneumomediastinum with Ascending Emphysema within the Spinal Canal
}

\author{
Keishi Oda, Hiroaki Ikegami, Issei Ikushima and Kazuhiro Yatera
}

Key words: pneumomediastinum, emphysema, spinal canal

(Intern Med 56: 1117-1118, 2017)

(DOI: 10.2169/internalmedicine.56.8136)
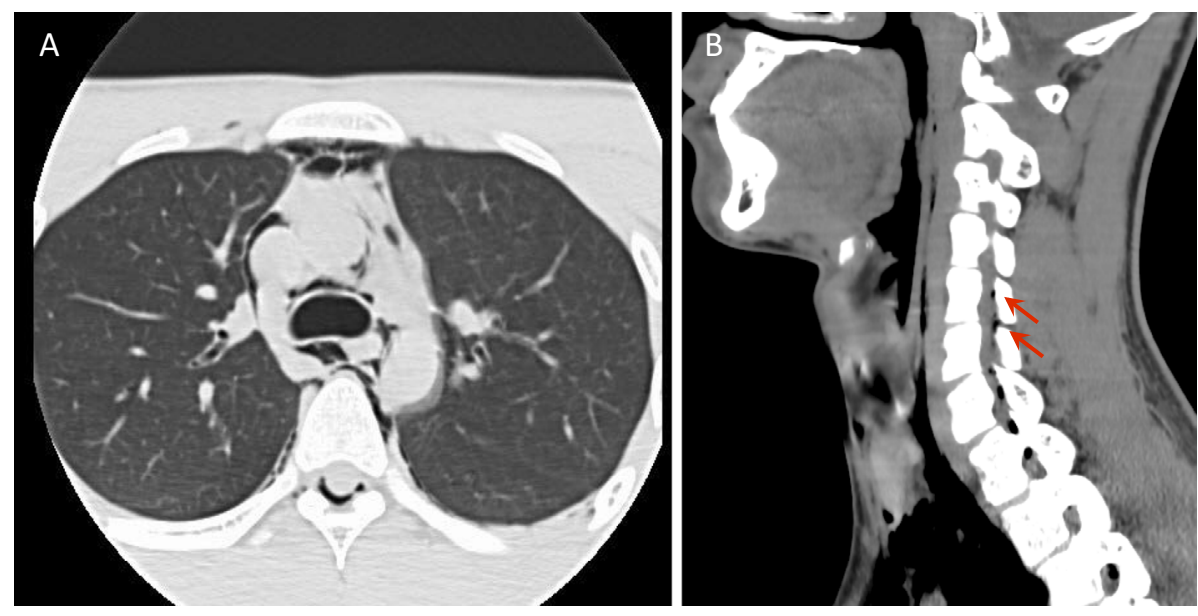

Picture 1.

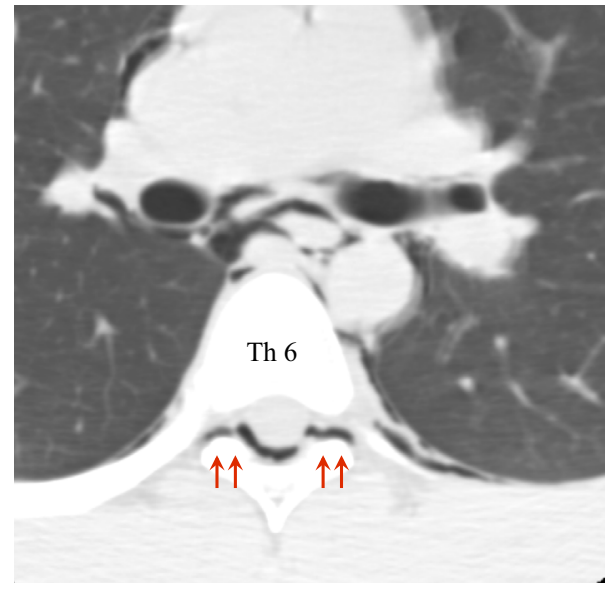

Picture 2.

A 16-year-old boy vomited due to heatstroke during a soccer game but continued to train hard after the game. He was admitted to our hospital for chest discomfort three days later. Chest radiograph demonstrated pneumomediastinum, and computed tomography of the neck revealed emphysema within the spinal canal (Picture 1A) at cervical level 5 (Picture $1 \mathrm{~B}$, red arrows). Barium esophagography revealed no fistulas. He was diagnosed with spontaneous pneumomediastinum and treated conservatively by bed rest. Five days after admission, he was discharged from our hospital. Although a previous study reported that pneumomediastinum patients occasionally have emphysema within the spinal canal (1), emphysema up to cervical level 5 is extremely rare. This rare condition was thought to be an aftereffect of emphysema within the mediastinum through the intervertebral foramen (Picture 2, red arrows) ascending to the spinal canal due to continuous hard excise.

The authors state that they have no Conflict of Interest (COI).

Department of Respiratory Medicine, University of Occupational and Environmental Health, Japan

Received for publication August 17, 2016; Accepted for publication August 24, 2016

Correspondence to Dr. Keishi Oda, oda-keishi@med.uoeh-u.ac.jp 
Intern Med 56: 1117-1118, 2017 DOI: 10.2169/internalmedicine.56.8136

\section{Reference}

1. Belotti EA, Rizzi M, Rodoni-Cassis P, Ragazzi M Zanolari-Caledrerari M, Bianchetti MG. Air within the spinal canal in spontaneous pneumomediastinum. Chest 137: 1197-1200, 2011.
The Internal Medicine is an Open Access article distributed under the Creative Commons Attribution-NonCommercial-NoDerivatives 4.0 International License. To view the details of this license, please visit (https://creativecommons.org/licenses/ by-nc-nd/4.0/).

(C) 2017 The Japanese Society of Internal Medicine http://www.naika.or.jp/imonline/index.html 